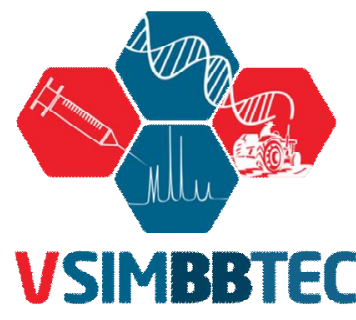

Londrina 2015

\title{
V SIMPÓSIO DE BIOQUÍMICA E BIOTECNOLOGIA
}

\author{
05 a 07 de agosto de 2015, Londrina - PR
}

\section{Potencial Biossortivo de Pleurotus ostreatus}

\author{
Caroline Aparecida Vaz de Araujo ${ }^{1}$, Elidiane Andressa Rodrigues ${ }^{1}$, Giselle Maria \\ Maciel $^{2}$, Fabíola Dorneles I nácio ${ }^{3}$, Rosane Marina Peralta ${ }^{1}$, Cristina Giatti Marques de \\ Souza' \\ ${ }^{1}$ Universidade Estadual de Maringá - Departamento de Bioquímica CEP 87020-900 Maringá - Paraná - E- \\ mail: (carolinearaujo1703@gmail.com) \\ ²Universidade Tecnológica Federal do Paraná - Departamento de Química e Biologia CEP 80230-901 \\ Curitiba - Paraná \\ ${ }^{3}$ Instituto Federal do Paraná - J acarezinho - Paraná CEP 84600-000
}

Introdução: Nos últimos anos, fármacos têm sido detectados com frequência no âmbito mundial em efluentes das estações de tratamento de esgoto, águas superficiais, etc. São considerados micropoluentes, pois são encontrados nas concentrações de $\mathrm{ng} / \mathrm{L}$ a $\mu \mathrm{g} / \mathrm{L}$. A entrada contínua de fármacos pode levar efeitos negativos para os seres humanos e o ecossistema aquático. Sendo assim, o objetivo do trabalho foi avaliar o potencial de Pleurotus ostreatus em remover os antibióticos trimetoprima e sulfametoxazol. Métodos: P. ostreatus foi utilizado na forma de pellets (após 5 dias de crescimento sob agitação em meio batata dextrose 1\%). Antes do inóculo, a biomassa passou por tratamento de calor (autoclavado por 15 min. a $121^{\circ} \mathrm{C}$ ) e ficaram imersos em soluções de $\mathrm{HCl}, \mathrm{NaOH}$ e $\mathrm{NaCl}(0,1 \mathrm{M})$. A biomassa (73 $\mathrm{mg}$ ) foi inoculada em meios contendo $50 \mathrm{mg} / \mathrm{L}$ de trimetoprima (TMT) e sulfametoxazol (SMZ). Os cultivos ficaram sob agitação a $120 \mathrm{rpm}, 28^{\circ} \mathrm{C}$ por 24 horas. Análises em HPLC foram feitas para verificar de remoção dos antibióticos. A fase móvel foi uma mistura de ácido fórmicoacetonitrila a 77:23 (v/v) com um vazão de $0,5 \mathrm{mLmin}^{-1}, 40^{\circ} \mathrm{C}$ e em $265 \mathrm{~nm}$. Os dados foram submetidos ao teste ANOVA e comparados pelo teste Tukey $(p<0,05)$. Resultados: Houve um aumento significativo na capacidade biossortiva para TMT com a biomassa tratada com NaCl $(56,23 \% ; 28,11 \mathrm{mg} / \mathrm{g}$ de biomassa seca). Não houve diferença significativa para a adsorção de SMZ sendo que o melhor tratamento foi o $\mathrm{HCl}(52,23 \% ; 26,11 \mathrm{mg} / \mathrm{g}$ de biomassa seca. Biomassa tratada com NaOH teve menor adsorção para TMT (34\%) e SMZ (41,83\%). Análises em HPLC mostraram que o tempo de retenção para TMT e SMZ foi de aproximadamente 5 e 10 minutos, respectivamente. Conclusões: Nossos resultados sugerem que biomassa de $P$. ostreatus pode ser utilizada como biossorvente para o tratamento alternativo de efluentes aquosos.

Agências de Fomento: Capes, CNPq, Fundação Araucária

Palavras-chave: biossorção, antibióticos, basidiomiceto. 